\title{
Philosophiques
}

\section{Le libéralisme et la politisation de la culture}

\section{Will Kymlicka}

Volume 19, numéro 2, automne 1992

Une nation peut-elle se donner la constitution de son choix?

URI : https://id.erudit.org/iderudit/027194ar

DOI : https://doi.org/10.7202/027194ar

Aller au sommaire du numéro

Éditeur(s)

Société de philosophie du Québec

ISSN

0316-2923 (imprimé)

1492-1391 (numérique)

Découvrir la revue

Citer ce document

Kymlicka, W. (1992). Le libéralisme et la politisation de la culture.

Philosophiques, 19(2), 93-115. https://doi.org/10.7202/027194ar d'utilisation que vous pouvez consulter en ligne.

https://apropos.erudit.org/fr/usagers/politique-dutilisation/ 


\title{
LE LIBÉRALISME ET
}

\section{LA POLITISATION DE LA CULTURE}

\author{
par \\ Will Kymlicka
}

Le libéralisme contemporain a échoué à reconnaître le pluralisme culturel et à s'y adapter. Au Canada, cela a eu comme résultat une résistance injustifièe face aux revendications légitimes des Canadiens français et des peuples aborigènes. On impute communément cet échec au fait que le libéralisme est intrinsèquement trop « individualiste » ou trop « universaliste » pour comprendre le sens que les gens accordent au fait d'être membres d'une culture particulière.

Je crois que cette explication commune est erronée. D'abord, elle néglige le fait qu'historiquement, de nombreux libéraux ont défendu des formes varièes d'autodètermination pour les minoritès culturelles. Cela a été particulièrement le cas entre les deux guerres mondiales. Jexaminerai donc dans cette communication une explication différente, et plus historique, pour expliquer l'échec du libéralisme contemporain. Je soutiendrai que l'hostilité actuelle du libéral isme à l'égard des droits des minorités culturelles est pour une bonne part le résultat de trois changements survenus dans le monde de l'après-guerre: (a) une désillusion face au programme de protection des droits des minorités de la Société des Nations, (b) le mouvement américain de déségrégation raciale,

I. Ce texte a été traduit par Geneviève Sicotte. Il est en partie adapté de mon article "Liberalism and the Politicization of Ethnicity », Canadian Joumal of Law and Jurisprudence, vol. 4, n" 2 (Ig9), Pp. 239-256. 
et (c) le mouvement de « renaissance ethnique » parmi les groupes d'immigrants aux États-Unis. Chacun de ces facteurs a façonné, mais a aussi déformé, la pensée libérale au sujet des droits des minorités culturelles. Bien qu'aucun de ces événements ou de ces mouvements ne soit spécifiquement canadien, chacun a contribué à la formation d'une nouvelle orthodoxie libérale qu'ont adoptée, peut-être sans s'en rendre compte, les libéraux canadiens.

Toutefois, avant de me tourner vers ces données historiques, il est important de clarifier l'idée de pluralisme culturel.

\section{Etat multinationai et Etat polyethnique}

Il existe de nombreuses formes de pluralisme culturel, et bien des façons de les étiqueter; il convient donc de formuler certaines distinctions de base. Il y a deux sources principales de pluralisme culturel. L'une est la coexistence de plusieurs cultures dans un État donné, « culture » signifiant une communauté historique, assez complète au plan des institutions, occupant un territoire ou une patrie donnés, et partageant une langue et une histoire propres. La « culture » dans cette acception est étroitement lièe à l'idée de « nation » ou de « peuple »- en fait, chacun de ces termes sert souvent à définir les autres. Par conséquent, un pays qui abrite plus d'une culture n'est pas un Etat-nation, mais plutôt un Etat multinational, où les cultures plus petites forment des « minorités nationales », ou « cultures minoritaires ». L'intégration de diverses cultures en un seul Etat peut être involontaire, par exemple quand une communauté culturelle est envahie et conquise par une autre, ou quand sa patrie devient graduellement occupée par des colons qui conservent leur culture d'origine. Mais la formation d'un État multinational peut aussi être volontaire, lorsque différentes cultures s'entendent pour former une fédération pour leur bénéfice mutuel.

La seconde source de pluralisme culturel est l'immigration. On retrouvera un pluralisme culturel dans un pays qui accepte comme immigrants un grand nombre d'individus et de familles provenant d'autres cultures, et qui leur permet de conserver certaines de leurs particularités ethniques. Dans ces circonstances, on attend des immigrants qu'ils s'intègrent aux institutions publiques de la ou des cultures existantes, mais on n'exige pas ou on n'attend pas d'eux qu'ils rejettent tous les aspects de leur patrimoine particulier et qu'ils assimilent complètement les normes culturelles en place. Les immigrants peuvent se regrouper pour 
continuer de pratiquer leurs coutumes ethniques, mais de tels groupes ne sont pas des nations, et ne constituent pas des cultures (complètes). Leur caractère distinct se manifeste dans la vie privee des individus, et ne doit pas affecter leur intégration aux institutions - ils participent quand même à la culture dominante et parlent la langue de la majorité. Un pays accueillant une immigration importante de ce type comprendra divers " groupes ethniques » composant des sous-cultures plus ou moins intégrées, et sera donc caractérisé par une «polyethnicité ».

Un même pays peut être à la fois multinational Isuite à une colonisation, à une conquête ou à la création d'une confédération) et polyethnique (suite a une forte immigration). En fait,tous ces modèles se retrouvent au Canada: les Amérindiens ont été écrasés par les colons français, les Français ont été conquis par les Anglais, quoique leurs présentes relations puissent être considérées comme le résultat d'une fédération volontaire, et les Anglais et les Français ont accepté des immigrants à qui l'on permet de conserver partiellement leurs caractéristiques ethniques. Le Canada est donc à la fois multinational et polyethnique. Ces deux étiquettes sont moins populaires que le terme « multiculturel». Mais ce terme peut porter à confusion, précisément parce qu'il crée une ambigu ité entre multinational et polyethnique. Certains Canadiens français se sont ainsi opposés aux politiques de «multiculturalisme » du gouvernement canadien parce qu'ils croient que cela réduit leurs revendications nationales à ce qui ne relèverait que de l'ethnicité. O'autres, à l'inverse, ont eu la crainte (ou l'espoir) que cette politique soit conçue pour traiter les groupes d'immigrants en tant que nations, et qu'elle donne par conséquent son aval au développement de cultures complètes détenant toutes leurs institutions en parallèle avec les cultures française et anglaise. En réalité, aucune de ces deux craintes n'était justifiée, car le «multiculturalisme » est une politique qui a pour but de permettre la polyethnicité au sein des institutions nationales anglaises et françaises. Comme le dit Burnet,

la culture, y compris la langue, ne peut être maintenue et développée qu'en étant présente dans tous les aspects de la vie. Dans cette optique, il ne peut pas avoir ete dans les intentions de la politique de promouvoir le multiculturalisme: le fait qu'il devait y avoir un cadre bilingue - anglais et français - rend cela évident Les concepteurs de cette politique avaient plutôt en tête d'appuyer la polyethnicité ${ }^{2}$.

2. J. Burnet, «Multiculturalism, Immigration, and Racism », Canadian Ethnic Studies, 7, 1975, P. 36. (NDLT: cette citation et les suivantes sont librement traduites.) 
Puisque le terme «multiculturel » suscite ce type de confusion, j'utiliserai les termes «multinational » et « polyethnique » pour désigner les deux formes principales de pluralisme culturel.

Dans les pays culturellement pluralistes, les modalités de la reconnaissance de l'ethnicité et de la nationalité par l'État sont une importante source de conflit. Quelles sont les langues qui devraient être reconnues dans les parlements, dans la fonction publique et devant les tribunaux? Est-ce que toute nation ou tout groupe ethnique devrait avoir droit à des institutions et à un système d'éducation fonctionnant dans sa langue et financés par des fonds publics? Les subventions de l'État devraient-elles être distribuées par des organismes nationaux ou ethniques? Les postes politiques devraient-ils être réservés aux membres de nations ou groupes ethniques particuliers, ou devraient-ils être répartis selon un principe de proportionnalité nationale ou ethnique? Les nations devraient-elles avoir un droit de veto sur les décisions concernant l'immigration, les communications, l'éducation, etc., susceptibles d'avoir un impact sur la culture?

Toute ces questions ont trait à ce que l'on pourrait appeler la «politisation de la culture ». Nous pouvons distinguer deux grandes catégories de revendications politiques, qui correspondent aux deux catégories de pluralisme culturel. Dans les États multinationaux, les nations constituantes ont tendance à réclamer une certaine forme d'autonomie politique ou de juridiction territoriale, de façon à garantir le libre développement de leur culture. A l'extrême, des nations peuvent souhaiter se séparer, si elles croient que leur autodétermination est impossible au sein du plus grand Etat ${ }^{3}$. Dans les Etats polyethniques, les groupes ethniques revendiquent le droit d'exprimer librement leurs particularités, par le biais par exemple d'associations et de journaux ethniques privés, sans que cela nuise à leur succès dans les institutions économiques et politiques de la culture dominante; ils ont tendance à réclamer de l'État un soutien pour mener à bien ces activités (comme des échanges et des festivals culturels, des études ethniques dans les écoles, une éducation bilingue). A l'extrême, les groupes ethniques peuvent exiger que des postes

3. Pour un survol des droits des minorités dans le monde, voir J. Sigler, Minority Rights: A Comparative Analysis, Westport, Greenwood Press, 1983; F. Capotorti, Study on the Rights of Persons Belonging to Ethnic, Religious and Linguistic Minorities, UN Doc. E/CN 4/Sub.2/384 Rev. I, New York, Nations Unies, 1979. 
politiques leur soient réservés, proportionnellement à leur population, et que des subventions de l'État soient distribuées par l'entremise d'organismes ethniques.

\section{I'ORTHODOXIE IIBÉRAIE ACTUELIE}

Ces questions constituent la plus grande part de la vie politique des pays pluralistes. Elles sont pourtant presque entièrement négligées par la philosophie politique libérale contemporaine. Les philosophes libéraux abordent rarement la question des diffèrences entre les États-nations et les États polyethniques ou multinationaux, et n'estiment apparemment pas que la pluralité culturelle soulève d'importantes questions pour la politique libérale. En dépit de ce vide théorique, une certaine vision de la culture a fini par être acceptèe à titre de position libérale orthodoxe.

Les libéraux contemporains, dans la mesure où ils abordent le sujet, considèrent la culture de la même façon que la religion ils la voient comme quelque chose que les gens sont libres de pratiquer dans leur vie privée, mais qui n'est pas l'affaire de l'Etat. Tout comme il exclut l'établissement d'une religion officielle, le libéralisme rejette l'établissement de cultures officielles ayant un statut privilégié face à d'autres allégeances culturelles. Dans une société libérale, « l'État érige un modèle où l'appartenance à un groupe [culturel] est purement privée let est] une question changeante de choix personnel et de degrè ${ }^{4}$.

L'Etat ne s'oppose pas à ce que les gens expriment librement leur attachement culturel particulier, mais il n'encourage pas non plus cette expression - pour employer l'expression de Glazer, il réagit plutôt par une « neutralité bienveillante ». Les groupes ethniques et nationaux « sont protégés contre la discrimination et les préjugés, et on leur accorde la liberté, comme à tous les individus et groupes, de conserver la part qu'ils veulent de leur héritage ethnique ou de leur identité distincte, à condition que cela n'empiète pas sur les droits des autres $\gg^{5}$. Mais leurs efforts en ce sens sont purement privés, et il n'appartient pas aux organismes publics d'attacher des identités légales ou des incapacités à l'appartenance culturelle ou à l'identité ethnique. L'État adhère au « principe de séparation entre l'Etat et

4. N. Glazer, "Individual Rights Against Group Rights », dans A. Tay et E. Kamenka, (dir.), Human Rights, London, Edward Arnold, 1978, p. 98.

5. N. Glazer, Ethnic Dilemmas: $1964-1982$, Cambridge, Harvard University Press, I983, p. 124. 
la société, qui fait de la religion et de l'appartenance ethnique une affaire privée. En ce sens, la séparation de l'État et de la société est au coeur de la démocratie libérale $»^{6}$. Puisque la culture est une affaire privée, les libéraux tendent à s'opposer à « toute reconnaissance gouvernementale ou légale » des groupes ethniques, et sont contre l'utilisation de "critères ethniques » dans l'attribution des droits, des ressources et des devoirs $\gg^{7}$. De la même façon, les libéraux s'opposent à l'octroi de "statut spécial » à des entités politiques contrôlées par des groupes ethniques ou nationaux.

Un problème se pose toutefois immédiatement avec les langues officielles. L'État accorde certainement une reconnaissance au moins partielle à une culture lorsqu'il décide quelle langue sera employée dans le système d'éducation public ou dans la prestation de services d'État. C'est là un fait gênant pour les tenants de la " neutralité bienveillante », et il est remarquable de constater à quel point les droits linguistiques sont rarement discutés dans la théorie libérale contemporaine. Il y a cependant eu des tentatives pour concilier l'existence de langues officielles avec la neutralité bienveillante. Selon Knopff, la langue a deux fonctions: elle peut fonctionner comme un véhicule de transmission d'une culture particulière, mais elle peut aussi fonctionner comme un « moyen de communication culturellement neutre, ou utilitaire, qui permet à des individus de différentes cultures de participer à une même communauté politique $»$. En privilégiant la fonction utilitaire, les gouvernements peuvent « promulguer des langues officielles sans pour autant décréter l'existence de cultures officielles [...] en promulguant des "langues officielles", on n'implique pas nécessairement que les cultures que ces langues transmettent et représentent deviennent par conséquent les "cultures officielles" ». La culture « reste une affaire purement privée $»$, car bien que le français et l'anglais bénéficient d'un

6. H. Brotz, « Multiculturalism in Canada: A Muddle », Canadian Public Policy, 6, ig80, p. 44. Cf. Glazer, Dilemmas, Art. cit., p. I24.

7. $\mathrm{M}$ Gordon, « Toward a General Theory of Racial and Ethnic Group Relations », dans N. Glazer et D. Moynihan, (dir.), Ethnicity, Theory and Experience, Cambridge, Harvard University Press, 1975, p. 105. Voir aussi J. Porter, « Ethnic Pluralism in Canada », Ibid., p. 295; J. Ajzenstat, « Liberalism and Assimilation: Lord Durham Revisited ", dans S. Brooks, (dir.), Political Thought in Canada: Contemporary Perspectives, Toronto, Irwin, 1984, PP. 251252.

8. R. Knopff, « Language and Culture in the Canadian Debate: The Battle of the White Papers ", Canadian Review of Studies in Nationalism, 6 (1979), p. 67. 
soutien officiel en tant que langues « utilitaires », toutes les langues sont sur le même pied pour ce qui est de l'allégeance «culturelle ${ }^{9}$.

Bien que la distinction entre les fonctions utilitaire et culturelle de la langue puisse être remise en question, nous avons maintenant les grandes lignes de l'orthodoxie libèrale actuelle sur la culture. Les libéraux ont invoqué l'idéal de neutralité bienveillante pour attaquer l'ensemble des propositions visant la politisation de la culture au Canada, qu'il s'agisse des revendications des Canadiens français pour leurs droits nationaux ${ }^{10}$, des revendications des peuples inuit et amérindiens pour leurs droits nationaux et aborigènes ${ }^{\text {II }}$, ou des réclamations des groupes ethniques pour bénéficier de subventions gouvernementales sous la politique du multiculturalisme ${ }^{\mathrm{I} 2}$. Ce conflit entre les exigences du libéralisme et les revendications des groupes culturels pour une reconnaissance publique a mené à une schizophrénie dans la façon dont les politiciens et les tribunaux canadiens traitent de la question de l'ethnicité et de la nationalité. Notre culture et nos institutions politiques reconnaissent tout à la fois l'égalité libérale et les droits des minorités, et pourtant chacun a été affaibli par l'autre ${ }^{13}$.

\section{LA CULTURE ET LA TRADITION IIBÉRALE}

Mais les libéraux adhèrent-ils à cette vision de la culture? L'orthodoxie actuelle veut que le libéralisme se soit toujours

9. R. Knopff, Ibid, pp. 67 et 70.

Io. Knopff, " Liberal Democracy and the Challenge of Nationalism in Canadian Politics ", Canadian Review of Studies in Nationalism, 9, 1982, Pp. 2939; F. I. Morton, « Group Rights Versus Individual Rights in the Charter: The Special Cases of Natives and the Quebecois », dans N. Nevitte et A. Kornberg, (dir.), Minorities and the Canadian State, Oakville, Mosaic Press, 1985, pp. $77^{-8} 3$.

II. F. L. Morton, Ibid., pp. 73-77; B. Schwartz, First Principles, Second Thoughts: Aboriginal Peoples, Constitutional Reform and Canadian Statecraft, Montreal, The Institute for Research on Public Policy, 1986, ch. I. Cf. M. Asch, Home and Native Land: Aboriginal Rights and the Canadian Constitution. Toronto, Methuen, 1984, pp. $75^{-88}$ et 100-104; G. Dacks, A Choice of Futures: Politics in the Canadian North, Toronto, Methuen, 1981, pp. 63-79; J. Ponting et R. Gibbins, Out of Irrelevance: $A$ socio political introduction to Indian affairs in Canada, Toronto, Butterworth, 1980, pp. 327-331.

12. H. Brotz, Art. cit., pp. 44-45; L Roberts et R. Clifton, « Exploring the Ideology of Multiculturalism », Canadian Public Policy, 8, 1982, pp. 90-93.

13. Jexamine cette tension dans Liberalism, Community, and Culture, Oxford, Oxford University Press, 1989, ch. 7. 
opposé à la politisation de la culture, et que les revendications des groupes culturels pour obtenir une reconnaissance politique constituent une déviation récente et répressive par rapport à la pratique liberale établie depuis longtemps ${ }^{14}$. Cela n'est pas vrai. Les droits des minorités ont constitué une part importante de la théorie et de la pratique libérales entre les deux guerres mondiales. Hobhouse, par exemple, a dit que « la pensée politique la plus libérale » de son époque avait admis la nécessité de reconnaitre les droits des minorités pour assurer « l'égalité sociale $»^{15}$. Il y a plus d'une façon de satisfaire les exigences légitimes des minorités nationales, mais « manifestement, ce n'est pas par l'égalité des votes que l'on peut y arriver. La minorité nationale ne veut pas simplement des droits égaux à ceux des autres. Elle revendique sa propre façon de vivre $\gg^{16}$. L'une des manifestations de cet engagement libéral fut le programme de protection des minorités mis de l'avant sous l'autorité de la Société des Nations pour diverses minorités européennes.

Certains libéraux se sont opposés aux droits des minorités, mais pas parce qu'ils adhéraient au principe de « neutralité bienveillante ». Ils se préoccupaient non de justice, mais de stabilité. Ils croyaient, avec Mill, que les institutions libres sont « quasi impossibles » dans un État multinational:

Dans un peuple où il n'existe pas de liens affectifs entre les individus, surtout si ceux-ci lisent et parlent diffèrentes langues, l'opinion publique unifiée nécessaire au fonctionnement des institutions représentatives ne peut pas exister [...] Cest en général une condition nécessaire à l'existence des institutions libres que les frontières des gouvernements coïncident dans l'ensemble avec les frontières des nationalités ${ }^{17}$.

14. Voir par exemple J. Ajzenstat. The Political Thought of Lord Durham, Kingston, McGill-Queen's University Press, 1988, pp. 91-92.

15. L T. Hobhouse, Social Development: Its Nature and Conditions, London, George Allen and Unwin, 1966, pp. 297 et 299.

16. Hobhouse, Social Evolution and Political Theory, New York, Columbia University Press, 1928, pp. 146-147, of. R. F. A. Hoernle, South African Native Policy and the Liberal Spirit, Cape Town, Lovedale Press, 1939, pp. 123-125, 136138 et $18 \mathrm{r}$.

17. J. S. Mill, Considerations on Representative Government, dans H. Acton, (dir.), Utilitarianism, Liberty, Representative Government, London, J. M. Dent and Sons, 1972, pp. 230 et 233; cf. T. H. Green, Lectures on the Principles of Political Obligation, London, Longmen's, Green, \& Co., 1941, Pp. I30-13I; P. Rich, « T. H. Green, Lord Scarman and the issue of ethnic minority rights in English liberal thought », Ethnic and Racial Studies, 10, 1987, p. 155. 
Pour les libéraux tels que Mill et T.H. Green, la démocratie est le gouvernement «par le peuple », mais ce gouvernement n'est possible que si « le peuple » est « un peuple », c'est-à-dire une nation. Les membres d'une démocratie doivent partager un même sentiment d'allégeance politique, et une nationalitè commune est considérée comme la condition nécessaire à cette allégeance. Selon ce courant de la pensée libérale, puisqu'un Etat libre doit être un Etat-nation, on doit agir face aux minorités nationales soit en les assimilant de force, soit en redessinant les frontières, mais pas en s'appuyant sur le concept de droits des minorités ${ }^{18}$.

Ainsi, l'orthodoxie libérale actuelle masque la diversité des perspectives libérales antérieures sur les droits des minorités. Notons qu'aucune de ces positions antérieures n'endosse l'opinion actuelle voulant que l'État doive traiter la culture comme une affaire privée. Au contraire, la première perspective prône une reconnaissance légale des cultures minoritaires, et la seconde rejette le concept de droits des minorités non pas parce qu'elle rejette l'idée d'une culture officielle, mais précisément parce qu'elle soutient qu'il doit y avoir une seule culture officielle.

Nous avons maintenant un tableau sommaire à la fois de l'orthodoxie actuelle et de l'ensemble des perspectives antérieures que cette orthodoxie a supplantees. Nous pouvons donc commencer à examiner les causes de ce changement.

\section{L'ÉCHEC DU TRAITÉ DES MINORUTÉs}

Le premier changement important dans l'opinion libérale est venu de l'échec du programme de protection des minorités de la Société des Nations et du rôle que cela a joué dans le déclenchement de la Seconde Guerre mondiale. Le programme accordait une reconnaissance internationale aux minorités germanophones de Tchécoslovaquie et de Pologne. Les nazis encouragèrent ces minorités à manifester des revendications et à loger des plaintes contre leurs gouvernements. Quand les gouvernements tchèque et polonais refusèrent, ou furent même incapables de satisfaire les exigences de plus en plus grandes de leurs minorités allemandes, les nazis se servirent de ce prétexte pour justifier une agression. Cette manipulation du programme de la Société

I8. N. Glazer, Dilemmas, p. 298. Pour un représentant actuel de l'école de Mill, voir P. van den Berghe. The Ethnic Phenomenon, New York, Elsevier, Ig8I, ch. 2. 
des Nations par les nazis, de même que la coopération manifestée par les minorités allemandes, entraîna « une forte réaction contre le concept de protection internationale des Iminorités nationalesl ... la réalité brutale était que les hommes d'Etat, généralement appuyés par une opinion publique profondément impressionnée par la perfidie de minorités irrédentistes et déloyales, étaient disposés à restreindre, plutôt qu'à élargir, les droils des minorités $\gg$. $\$$. Cette réduction des droits des minorités fut effectuée non pas dans l'intérêt de la justice, mais par des gens « dont le système de référence plaçait les intérêts de l'Etat national au rang de valeur suprême... [La majorité nationalel avait intérêt à assurer la sécurité de l'État et à stabiliser les institutions, même si le prix devait en être la disparition des minorités culturelles et l'imposition d'une homogénéité forcée à la population $»^{20}$.

Aux Nations Unies, on souhaitait explicitement ne pas aborder la question des droits des minorités; ce n'est d'ailleurs que récemment que cet organisme a accepté de reconsidérer la légitimité des revendications reliées aux droits des minorités ${ }^{2 \mathrm{I}}$. La crainte que ces minorités ne se montrent déloyales lou simplement indifférentes) continue d'entraver la discussion concernant le bien-fondé de ces revendications, à la fois sur le plan international et dans la politique intérieure de plusieurs pays ${ }^{22}$.

\section{LA DÉSÉGRÉGATION RACIAIE AUX ETtaTS-UNIS}

Si le rejet libéral moderne du concept de droits des minorités commença avec des inquietudes concernant la stabilité politique, il se drapa dans la robe de la justice lorsqu'il fut associé à la déségrégation raciale. Dans la cause Brown us Board of Education, la

19. L Claude, National Minorities: An Intemational Problem, Cambridge, Harvard University Press, 1955, Pp. 57 et 69.

20. I. Claude, Ibid., pp. 80-8I. Cette vision est similaire à celle de Mill, mais tandis que ce dernier était préoccupé par la stabilité intérieure, les hommes d'Etat d'après-guerre se préoccupaient en premier lieu de la paix internationale. Toutefois, le résultat fut le même: les questions concernant le caractère juste des droits des minorités furent subordonnées aux exigences plus pressantes de stabilité.

21. L Sohn, "The Rights of Minorities 》, dans L. Henkin, (dir.), The Intemational Bill of Rights: The Covenant on Civil and Political Rights, New York, Columbia University Press, $198 \mathrm{r} ; \mathrm{P}$. Thornberry, Intemational Law and the Rights of Minorities, Oxford, Oxford University Press, 1991.

22. D. Maybury-Lewis, "Living in Leviathan: Ethnic Groups and the State », dans Maybury-Lewis, (dir.), The Prospects for Plural Societies, Washington, American Ethnological Society, 1984, pp. 222-227. 
Cour suprême américaine mit fin au système ségrégationniste d'écoles séparées pour. les enfants blancs et noirs dans le Sud. Cette décision, et dans son ensemble le mouvement des droits civils, eut une énorme influence sur la vision américaine de l'égalité raciale. Le nouveau modèle de justice raciale en fut un de lois « colour-blind $»^{23}$, qui venaient remplacer le « traitement séparé mais égal » représentant dorénavant le paradigme de l'injustice raciale. L'influence de ce jugement se fit aussi rapidement sentir dans d'autres domaines que celui des relations raciales; il semblait en effet mettre de l'avant un principe également applicable aux questions concernant la culture. Selon ce principe, l'injustice consiste en une exclusion arbitraire des institutions dominantes de la société, et l'égalité consiste en la non-discrimination et en des chances égales de participer. Vue sous cet angle, la législation donnant des institutions séparées aux cultures minoritaires ne semble pas différente de la ségrégation des Noirs. Ainsi, la cause Brown eut comme extension naturelle que l'on retira leur statut spécial aux minorités culturelles, et que l'on encouragea leur participation égale au courant dominant de la société. Ce raisonnement sous-tendait la proposition que fit le gouvernement canadien en 1969 et qui visait à retirer leur statut constitutionnel spécial aux Amérindiens ${ }^{24}$; le jugement Brown fut aussi cité par la Cour suprême du Canada pour renverser une loi promulguée en vertu de ce statut ${ }^{25}$. La formule de justice raciale mise de l'avant par le jugement Brown fut enfin invoquee pour contester les droits des Amérindiens des Etats-Unis et ceux des minorités nationales en droit international ${ }^{26}$.

Mais en fait, le jugement Brown ne contient rien pouvant amener l'application de la formule colour-blind aux droits des

23. Jeu de mot intraduisible, colourblind, littėralement « aveugle aux couleurs », signifiant « daltonien » (NDLT).

24. "Statement of the Government of Canada on Indian Policy », dans R. Bowles et al., (dir.), The Indian: Assimilation, Integration or Separation?, Scarborough, Prentice-Hall, 1972, p. 204 ( $«$ des services égaux mais séparés ne constituent pas un traitement réellement égal ») et p. 202 (« le but final d'enlever de la constitution toute référence spécifique aux Amérindiens [...] doit être constamment gardé à l'esprit »).

25. Regina v Drybones (1970) S.C.R. 282 (« Les situations sociales dans Brown vs Board of Education et dans les cas présents sont évidemment très différentes, mais le concept philosophique de base reste le mème »).

26. R. Barsh et J. Henderson, The Road: Indian Tribes and Political Liberty, Berkeley, University of California Press, 1980, Pp. 24I-248; V. Van Dyke, Human Rights, Ethnicity and Discrimination, Westport, Greenwood Press, 1985, p. 194. 
minorités nationales. En effet, la Cour ne traitait tout simplement pas de la question des droits nationaux, comme le droit d'une culture à posséder les institutions autonomes nécessaires à son libre développement au sein d'un État multinational. Les ségrégationnistes ne soutenaient pas que les Blancs et les Noirs formaient différentes cultures, avec différentes langues et différentes littératures. Au contraire, toute leur argumentation reposait sur le fait que l'éducation que recevaient les Noirs dans les institutions séparées était identique à celle des Blancs. La question était donc de déterminer si l'on pouvait placer des groupes raciaux dans des institutions séparées, dans la mesure où ces institutions étaient identiques. La Cour statua que dans ces circonstances, la ségrégation constituait une inégalité inhérente, puisqu'elle serait perçue comme une « marque d'infériorité », comme un signe de racisme.

Rien dans ce jugement ne vient étayer l'affirmation voulant que les droits nationaux soient incompatibles avec l'égalité libérale. En fait, le jugement, si on l'examine de plus près, pourrait même constituer un argument pour la reconnaissance de ces droits. Considérons la situation des Amérindiens des Etats-Unis, dont les institutions séparées ont èté la cible d'attaques après l'arrêt Brown:

Alors que les Noirs ont ètè de force exclus (ségrégués) législativement de la socièté blanche, les Amérindiens - des peuples aborigenes ayant chacun leur culture, leur langue, leur religion et leur territoire - ont étè de force inclus (intégrès) législativement dans cette société. C'est ce que l'on entend par assimilation coercitive: le fait de contraindre par l'immersion une minorité ethnique, culturelle ou linguistique à se dèpartir de son caractère unique et de son identité et à $s^{\prime}$ intégrer au reste de la société ${ }^{27}$.

L'éducation intégrée pour les Amérindiens, tout comme l'éducation ségréguée pour les Noirs, est une « marque d'infériorité », car elle ne reconnait pas « l'importance et la validité de la communauté amérindienne » ${ }^{28}$. En fait, « l'intégration des enfants Amérindiens dans des écoles dominées par les Blancs a eu les mêmes effets négatifs, aux plans éducatif et affectif, que ceux que le jugement Brown a imputés à la ségrégation »; par conséquent, le «principe sous-jacent » qui a mis fin à la ségrégation des Noirs lC'est-à-dire l'interdiction des classifications raciales

27. M. Gross, "Indian Control for Quality Indian Education », North Dakota Law Review, 49, 1973, p. 244.

28. M. Gross, Ibid., p. 242. 
nuisibles à une minorité) devrait aussi mettre fin à l'intégration des Amérindiens inscrite dans la loi ${ }^{29}$.

Il ne faut pas conclure de cela que les Amèrindiens n'ont pas besoin d'être protégés contre le racisme. Mais alors que le racisme contre les Noirs provient du fait que les Blancs refusent d'accorder aux Noirs le statut de membres à part entière de la communauté, le racisme contre les Amérindiens provient essentiellement du fait que les Blancs refusent de considèrer les Amérindiens comme des peuples distincts, ayant leurs propres cultures et leurs propres communautés. Malheureusement, la place centrale prise par le mouvement des droits civils a empêché les gens de voir les problèmes spécifiques soulevés par l'existence de minorités nationales ${ }^{30}$.

\section{LA RENAISSANCE ETHNIQUE AMÉRICAINE}

Pour de nombreux libéraux, l'idée selon laquelle les droits des minorités sont injustes et suscitent la division se trouva confirmée par le rôle que jouèrent ces droits dans le mouvement de renaissance (ou revival) ethnique qui secoua les États-Unis durant les années 60 et 70 . Ce mouvement commença par affirmer qu'il était légitime (et pas " non-américain ») pour les groupes ethniques d'exprimer leurs caractéristiques spécifiques. A l'époque, l'objectif explicite des politiques d'immigration ètait d'atteindre à une " anglo-conformité », c'est-à-dire de convertir les immigrants aux normes culturelles issues de l'héritage anglais du pays. Les groupes qui étaient considérés comme incapables de s'adapter étaient l'objet de restrictions à l'immigration, et l'on attendait de toute personne qui était admise qu'elle coupe ses anciennes racines ethniques. Ces restrictions et ces attentes furent progressivement abandonnées au cours des années 60 et 70 , à la fois aux Etats-Unis et au Canada, alors que les gouvernements acceptèrent

29. M. Gross, Ibid., pp. 245 et 248.

30. Comme le remarque Thomas Berger, « les médias américains pénètrent si profondement la vie canadienne que nous avons tendance à croire que nos propres problemes de relations raciales doivent être définis de la mème façon qu'ils le sont aux Etats-Unis. Ainsi, plusieurs de nos spécialistes en droit et de nos politicologues pensent qu'il faut reproduire l'expérience américaine. En L969, le gouvernement du Canada a adopté pour sa population autochtone une politique d'intégration et d'assimilation qui était basée sur une politique américaine développée dans les années 60 et s'appliquant aux Noirs. » (« Towards the Regime of Tolerance », dans S. Brooks, (dir.), Political Thought in Canada: Contemporary Perspectives, Toronto, Irwin, Ig84, p. 94. 
l'existence de «membres de groupes ethniques inintégrables 》 parmi les immigrants ${ }^{3}$.

Mais le mouvement de renaissance ethnique aux Etats-Unis donna bientôt lieu à de nouvelles revendications. L'une des conséquences de l'expression plus ouverte de l'identité ethnique fut que les groupes ethniques prirent davantage conscience de leur statut en tant que groupe. Il devint courant de mesurer la distribution du revenu ou des emplois en rapport avec l'origine ethnique. Les groupes qui réussissaient moins exigèrent des mesures d'amélioration ciblees sur des groupes particuliers, comme des quotas en éducation et dans l'emploi. D autres groupes, moins préoccupés de leur réussite dans les institutions dominantes de la société, insistèrent plutôt sur l'autodétermination culturelle et sur la nécessité d'institutions séparées dans lesquelles ils pourraient développer leur propre culture. C'est ainsi que de multiples façons, l'ethnicité devint de plus en plus importante dans la vie politique américaine.

Les libéraux américains ont entretenu une relation ambiguë avec le mouvement de renaissance ethnique. La plupart des libéraux ont accepté les revendications initiales concernant l'abandon du modèle d'anglo-conformité. Cependant, à mesure que les revendications ethniques se faisaient plus nombreuses, le soutien libéral diminua. Jexaminerai la discussion que fait Nathan Glazer du mouvement de renaissance ethnique, de façon à

3I. Cette adhésion partagée à l'anglo-conformité est dissimulée par le contraste trompeur entre le « melting-pot» américain et la « mosaïque ethnique » canadienne. Bien que l'expression « mosaïque ethnique » véhicule la connotation idéologique du respect de l'intégrité des cultures ethniques, en pratique cela signifiait uniquement que les immigrants venant au Canada pouvaient choisir de s'assimiler à l'une des deux cultures dominantes. Mais alors que le Canada est binational, la " tolérance difficile » dont faisaient preuve les francophones et les anglophones les uns envers les autres ne s'étendait pas aux ètrangers qui résistaient à l'assimilation ou que l'on croyait inassimilables. U. Porter, The Measure of Canadian Society, Toronto, Gage, 1979, p. 154l. A l'inverse, le « melting pot » faisait avant tout référence au mélange biologique des divers groupes ethniques par l'intermariage, et non pas au mélange de leurs pratiques culturelles. Comme l'expliqua Theodore Roosevelt, les "représentants de nombreuses races de l'ancien monde se fondent en un type nouveau », mais « le creuset dans lequel tous ces nouveaux types se fondent en un seul a été élaboré de 1776 à 1789 , et notre nationalitè a été dèfinitivement fixée dans tous ses éléments essentiels par les hommes de Washington's day ». (Theodore Roosevelt, dans M. Gordon, Assimilation in American Life: The Role of Race, Religion, and National Origin, New York, Oxford University Press, Ig64, p. I22.) 
comprendre comment les inquiétudes au sujet de la politisation des groupes d'immigrants aux États-Unis ont influencé la manière libérale de concevoir la culture en général.

Glazer croit que la politisation de l'ethnicité aux États-Unis est une tendance nouvelle et inquiètante. L'ethnicite n'a pas constitué la base de la politique américaine parce que la division fédérale des Etats-Unis « a précédé la création de notre grande diversité ethnique »:

[Eln l'absence de concentrations ethniques et raciales dominant un ou plusieurs Etats, ainsi que de concentrations ethniques qui auraient pu revendiquer des droits nationaux parce qu'elles se seraient établies sur le territoire américain avant de devenir une partie des Etats-Unis, la plupart des groupes ne purent concevoir de revendiquer des droits nationaux - par exemple, le droit d'utiliser leur langue dans le gouvernement d'un Etat, ou le droit de mettre sur pied des institutions reflétant leur culture ethnique distincte, ou encore le droit de faire sécession ${ }^{32}$.

Ce modèle américain d'une ethnicité dispersée et entremêlée, que Glazer appelle la « diversité ethnique du Nouveau Monde ", est fondamentalement différent du modèle d'Etat multinational de l'ancien monde. Les groupes américains «formulent rarement des revendications ethniques concrètes telles qu'on pourrait en rencontrer au sein de nations où les groupes ethniques forment des entités plus compactes, conscientes de leur identité et préservant leur culture ${ }^{33}$.

Le fait que les groupes ethniques américains ne formulent pas de revendications nationales ne prouve pas qu'ils soient victimes de racisme, puisque ces groupes n'ont aucune justification pour de telles revendications. Dans le cas de l'éducation en langue maternelle, par exemple, la plupart des Américains

sont venus dans ce pays non pas pour conserver une langue et une culture étrangères, mais avec l'intention [...] de s'américaniser le plus rapidement possible, et cela signifiait ld'adopterl la langue anglaise et la culture américaine. Ils cherchaient l'initiation a une nouvelle langue et à une nouvelle culture que l'école publique pouvait leur offrir (comme c'est le cas pour beaucoup d'immigrants aujourd'hui aussi), et s'il leur arrivait souvent, à mesure que le temps passait, de regretter ce qu'eux ou leurs enfants avaient perdu, c'était leur choix, plutôt qu'un choix imposé su $^{34}$.

Quand les immigrants choisissaient de quitter leur culture et de venir en Amérique, ils renonçaient volontairement à leur

32. N. Glazer, Dilemmas, Op. cit., Pp. $276^{-2} 77$.

33. Ibid., p. 283.

34. Ibid., P. 149 . 
citoyenneté nationale et aux droits qui y étaient associés. Cest la situation opposée que vivent les minorités nationales de l'ancien monde, où la négation des droits nationaux, comme par exemple l'éducation dans la langue maternelle, est un " choix imposé ».

La distinction entre les pays de l'ancien monde, qui sont « une fédération de peuples », et les pays d'immigrants, qui sont composés de groupes ethniques « dispersés, mêlés, assimilés let] intégrés $>35$ constitue le coeur de l'argument de Glazer contre la politisation de l'ethnicité aux États-Unis. Je crois aussi que cela est une distinction importante ${ }^{36}$. Il est evident que des groupes d'immigrants ne peuvent pas revendiquer les mêmes droits que des minorités nationales. Si je décide avec d'autres d'émigrer en Chine, nous n'avons pas le droit d'exiger que le gouvernement chinois nous accorde l'autonomie politique ou qu'il nous fournisse des services publics dans notre langue d'origine. Nous pourrions soutenir qu'une politique gouvernementale assurant des services en anglais enrichirait l'environnement culturel entier, et que donc tous pourraient en tirer profit. Mais nous n'aurions pas le droit à une telle politique, puisqu'en choisissant de quitter le Canada, nous aurions renoncé aux droits nationaux associès au fait d'être membre de notre communauté culturelle.

Toutefois, à mesure que le mouvement de renaissance ethnique s'intensifiait, certains groupes d'immigrants aux EtatsUnis en vinrent à adopter le langage et les attitudes des nations ou des peuples colonisés ${ }^{37}$. Ils qualifièrent les pressions sociales

35. Ibid., p. 227.

36. Certains groupes culturels ne cadrent exactement ni dans le camp des « minorités nationales», ni dans celui des « immigrants volontaires ». Par exemple, les Doukhobors ont immigré au Canada non pas volontairement en tant qu'individus, mais en masse, précisément a fin de préserver leur culture parcequ'ils étaient persécutés en Russie. Doutres groupes (par exemple les Hutterites et les Ukrainiens) sont venus volontairement, mais sur la promesse explicite des officiels de l'immigration canadienne qu'ils pourraient préserver leur culture et leurs structures sociales. Dans aucun de ces cas, on ne peut dire que ces gens ont librement choisi de renoncer aux droits accompagnant le fait d'être membres de leur communautè culturelle. Les arrangements fiscaux particuliers et les exemptions relatives a l'éducation pour les Hutterites et les Doukhobors montrent que notre système judiciaire reconnaît que certains groupes culturels ne cadrent pas exactement dans les catégories des minorités nationales ou des immigrants volontaires, et demandent donc un statut intermédiaire. Voir a ce sujet $W$. Janzen, Limits on Liberty: The Experience of Mennonite, Hutterite, and Doukhobour Communities in Canada, University of Toronto Press, Toronto, I9go.

37. N. Glazer, Op. cit., pp. IIo-in. 
visant l'assimilation d'« oppression », revendiquèrent leur «droit » à une reconnaissance étatique de l'ethnicité et exigèrent un soutien de l'État pour des institutions ethniques séparées. Pour Glazer, l'adoption de la rhétorique nationaliste par les groupes d'immigrants est totalement injustifiée. Les nouvelles revendications ne sont pas fondées, puisque l'immigration ne fut pas un choix imposé. De plus, ces revendications suscitent la division, car aucun groupe n'admettra qu'un autre se voie accorder des droits spéciaux ${ }^{38}$. Elles sont enfin irréalisables, car les groupes ethniques américains sont trop dispersés et assimilés pour exercer une autonomie collective. De plus, toute tentative de faire de ces groupes ethniques des « entités compactes, conscientes de leur identité et préservant leur culture $\gg$, ce qui serait nécessaire pour leur autonomie collective, demanderait que l'on fasse appel à la coercition puisque de nombreux immigrants désirent $s^{\prime}$ intégrer ${ }^{39}$.

Cest là l'argument de Glazer contre la politisation de l'ethnicité aux États-Unis, un argument dont l'appartenance libérale se décèle aisément en ce qu'il souligne le rôle du choix dans l'assimilation des immigrants et celui de la cœrcition dans l'assimilation des minorités nationales. Mais notons que cet argument, quelle que soit sa validité, ne constitue pas directement un argument contre les droits nationaux ${ }^{40}$. Ce que Glazer soutient, c'est que les groupes ethniques aux Etats-Unis ne sont pas des minorités nationales; il n'affirme pas que les minorités nationales n'ont aucun droit. Pourtant, tout comme dans le cas du jugement Brown, les liberraux ont eu tendance à généraliser à toutes les questions d'ethnicité les conclusions de son propos. En fait, Glazer lui-même tourne ses arguments comme pour faire en sorte qu'ils s'appliquent aux minorités nationales. Il note que même aux États-Unis, il existe des exceptions au modèle d'ethnicité du Nouveau Monde - les Amérindiens, les Mexico-américains, les Noirs, les Portoricains, etc. Relativement à plusieurs de ces groupes, les États-Unis sont (ou à tout le moins étaient) " une fédération de peuples ». Quand le Sud-Est se joignit aux

38. Ibid., pp. 228-229.

39. Ibid., p. 124.

40. Cela n'est pas non plus un argument contre les politiques existantes de "multiculturalisme », pourvu que celles ${ }^{-c i}$ ne soient pas considérées comme des questions de droits nationaux ou d'autonomie collective. Glazer estime toutefois que les risques de ccercition et de division sont si grands que même les formes modestes de soutien à la polyethnicité sont de mauvaises politiques, N. Glizer, Op.cil., p. 124. 
États-Unis, on reconnut les Hispano-américains en tant que culture distincte jou issant de droits spéciaux, même si ces droits leur furent enlevés lorsque les colons anglophones finirent par acquérir un statut majoritaire ${ }^{41}$. Les Amérindiens et les Portoricains sont encore aujourd'hui fédérés avec l'État américain en tant que peuples distincts ayant un statut politique spécial.

Glazer reconnaît que ces groupes « possèdent beaucoup plus de caractéristiques nationales ${ }^{42}$, et qu'ils revendiquent des droits nationaux correspondants:

A la fois les Noirs et les hispanophones sont dans une situation politique spécifique: les Noirs furent amenés en tant qu'esclaves, et les Mexicains et les Portoricains furent conquis. Les Amérindiens furent aussi conquis. Les groupes ethniques blancs, cependant, vinrent en tant qu'immigrants libres. Ainsi, les Noirs, les groupes hispanophones, les Amérindiens et peut-être quelques autres groupes, ont une base plus forte que les groupes européens pour réclamer que l'Etat soutienne leur culture distincte ${ }^{43}$.

Glazer admet que ces revendications pour la reconnaissance de droits nationaux «ont un solide fondement ${ }^{44}$.

Il s'oppose pourtant à la reconnaissance des droits des minorités nationales américaines. Il espère plutôt que « ces groupes, grâce à des politiques publiques adéquates visant à èliminer la discrimination, à corriger leur statut inférieur et à encourager leur acculturation et leur assimilation, deviendront assez semblables aux groupes ethniques européens et asiatiques, ces nations fantômes qui, réunies par la nostalgie et le sentiment, se regroupent seulement à l'occasion autour d'intérêts qui leur sont propres $\gg 45$. En terminant, Glazer souligne que la « neutralité bienveillante » convient aussi aux minorités nationales, bien que cela contredise son propre argument faisant

4I. Ibid., p. 277. Le cas des Métis est semblable à cela: leurs droits nationaux furent reconnus quand le Manitoba entra dans la confédération, puis abolis quand les colons anglais devinrent majoritaires dans la province.

42. Ibid., pp. $283-284$.

43. Ibid., p. 116 .

44. Ibid., p. IIg. Les Noirs américains ne cadrent ni dans le pattern de l'ethnicite du Nouveau monde, ni dans celui des minorites nationales. Ils n'ont pas choisi de quitter leurs cultures d'origine, et on ne leur a pas permis de préserver celles ${ }^{-c i}$ ou de créer une communauté nationale à l'intérieur des Etats-Unis. C'est la raison pour laquelle les droits qu'ils ont revendiqués en tant que groupe ont porte davantage sur des questions de justice compensatoire que sur des questions de droits nationaux.

45. Ibid., p. 284 . 
valoir la différence entre l'assimilation involontaire de nations minoritaires et l'assimilation volontaire des immigrants.

Pourquoi Glazer rejette-t-il les implications de son propre argument en ce qui concerne les droits nationaux? Par moments, il semble dire que l'adhésion des Américains au principe de neutralité bienveillante est essentiellement arbitraire. Selon lui, chaque pays peut choisir à son gré « de traiter la diversité multiethnique en l'ignorant officiellement ou en la reconnaissant officiellement », et chacun de ces choix est compatible avec les exigences de la justice ${ }^{46}$. Les Américains, toutefois, ont fait leur choix il y a longtemps déjà: ils ont décidé d'ignorer officiellement les groupes culturels, et cela fait maintenant partie de l'image que l'Amérique a d'elle-même. Il y a, dit-il,

une idéologie d'Etat, un consensus national, qui modele et determine l'attitude que prendront les immigrants et les groupes minoritaires envers les possibilités alternatives que sont, d'une part, le maintien et les droits des groupes, et d'autre part, l'intégration individuelle et les droits individuels I...l Les Etats-Unis, en depit de l'existence de la discrimination et de la ségrégation, avaient comme idéal national une identité ethnique nouvelle et unitaire, celle d'être Américain ${ }^{47}$.

Glazer ne soutient donc pas que les droits des minorités sont injustes, mais plutôt qu'ils sont « non-américains ».

Mais c'est là un argument bien faible. Qu'en est-il si le consensus national est bâti sur une insensibilité aux interêts des minorités nationales? De toute façon, la description que fait Glazer du consensus national est biaisée. Il soutient que le consensus doit soit accepter, soit rejeter la politisation de la culture. Mais le consensus national ne peut-il pas faire valoir ce sur quoi Glazer lui-même insiste, c'est-à-dire la différence entre les groupes d'immigrants et les minorités nationales? L'idéal national peut reconnaitre les droits légitimes des cultures minoritaires, tout en rejetant les revendications illégitimes des groupes d'immigrants. En fait, cela est bien près de la pratique reelle et du consensus national à la fois aux État-Unis et au Canada: les Amérindiens, les Inuit, les Canadiens français et les Portoricains se voient accorder de par nos lois un statut politique spécial qui n'est pas reconnu aux autres groupes ethniques. Ainsi, Glazer ne peut fonder son adhésion à là neutralité bienveillante envers les

46. Glazer, " Group Rights », p. g8.

47. Glazer, «Group Rights », p. 100. 
minorités nationales ni sur un argument de justice, ni sur un argument de convention.

Pourquoi alors est-il opposé à une reconnaissance des droits des minorités nationales? Après avoir affirmé que la politique «adéquate » est d'assimiler les Amérindiens, il poursuit en notant une « complication finale »:

Si la politique publique se trouve modifiee au point où, plutôt que de tenter de supprimer les groupes ethniques ou d'en ignorer l'existence en tant qu'élèment spécifique de la sociètè et de la politique américaines, elle accorde un statut distinct à certains groupes et commence à reconnaître dans la loi des droits à ceux qui en sont membres, cela ne suscitera-t-il pas une réaction de la part des autres groupes, dejà rendus à mi-chemin dans le processus d'assimilation, et ne commenceront-ils pas à s'affirmer à nouveau pour ne pas se retrouver en position désavantageuse ${ }^{48}$ ?

Voilà le point capital pour Glazer. Les Amérindiens qui désirent que soient reconnus leurs droits nationaux ont peutêtre la justice et la convention de leur côté, mais

le problème est que nous ne sommes pas une fèdération de peuples (comme le Canada ou l'Union soviétique), mais une fédération d'Etats, et que nos groupes ethniques sont déjà trop dispersés, trop mêlés, trop assimilès et trop intégrés pour permettre que soit appliquée sans confusion une politique qui placerait quelques-uns de ces groupes à part et leur accorderait un traitement spécial. Si nous essayons de le faire, plusieurs autres groupes se joindront au cortège des revendicateurs, ou tenteront de le faire, et nous devrons abandonner notre espoir d'une plus grande fraternité de tous les Américains [...IS Dans une société multiethnique, une telle politique ne peut qu'inciter un groupe apres l'autre à revendiquer un traitement spécial destiné à le protéger l... Ces revendications provoqueront, chez les groupes qui croient avoir droit a un traitement spécial mais ne l'ont pas, de l'animosité envers les groupes qui bénéficient déjâ d'un tel traitement ${ }^{49}$.

En d'autres termes, la reconnaissance des revendications légitimes des Amérindiens amènerait les groupes ethniques européens et asiatiques à exiger des privilèges illégitimes et provoquant la division, ce qui mettrait par conséquent en danger la « plus grande fraternitè de tous les Américains ».

Il vaut la peine de s'arrêter un instant pour examiner à quel point cet argument est faible. Premièrement, c'est un argument hypocrite: il se fonde sur l'importance de la distinction entre les minorités nationales et les groupes ethniques, mais il nie que

48. N. Glazer, Op. cit, p. 284.

49. Ibid., pp. $227^{-229 .}$ 
cette distinction puisse être effectuée ${ }^{50}$. Deuxièmement, c'est un argument ethnocentrique. Glazer soutient qu'il existe un «consensus national » en faveur de l'assimilation, mais il entend manifestement par cela un consensus parmi les groupes ethniques européens et asiatiques, puisqu'il admet que d'autres groupes veulent obtenir des droits nationaux. Il affirme que ce consensus a engendré une «fraternité de tous les Américains», mais il reconnaît que les Noirs, les Amérindiens, les hispaniques et les Portoricains en sont exclus. Il affirme que les droits nationaux devaient être rejetés afin d'éviter une animosité mutuelle. Ce qu'il désire véritablement éviter, cependant, c'est le ressentiment (injustifié) parmi les groupes ethniques européens et asiatiques, puisqu'il admet que les minorités nationales sont dejà let légitimement) pleines de ressentiment devant la négation de leurs droits nationaux. Les groupes d'immigrants ont, de façon illégitime, adopté le langage des droits nationaux, et pour combattre cette tendance menant à la division, Glazer refuse aux Amérindiens le droit légitime à l'utilisation de ce langage.

Il est difficile de ne pas conclure que les Amérindiens sont des pions que Glazer sacrifie pour préserver ce qui lui importe vraiment, c'est-à-dire la fraternité des groupes d'immigrants aux Etats-Unis. Les croyances de ces groupes ethniques sont selon Glazer ce qui définit l'idéal " national », et révèlent ce que sentent « tous les Américains ». Par conséquent, les revendications des Amérindiens ne sont pas évaluées selon leur valeur intrinsèque, mais selon leurs effets potentiels sur la « fraternité » des groupes d'immigrants. Cest ainsi par un décret arbitraire et ethnocentrique, de même que par la subordination explicite des intėrêts des minorités nationales à la fraternité des groupes ethniques, que Glazer défend son adhésion au principe des lois colour-blind, principe qui avait été présenté comme la caractéristique fondamentale de la justice libérale ${ }^{5 \mathrm{I}}$. Son rejet des droits nationaux n'est donc pas le produit de ses principes libéraux.

Pourtant, un grand nombre de libéraux américains partagent le point de vue de Glazer. On suppose généralement que les

50. Les délégués américains aux Nations Unies manifestent la même tendance, affirmant et niant alternativement les différences entre les groupes d'immigrants et les minorités nationales lorsqu'ils s'opposent à la protection internationale des droits des minoritès. Voir Sohn, Op. cit., pp. 272 et 279; W. McKean, Equality and Discrimination Under International Law, Oxford, Oxford University Press, 1983, pp. 70-71 et 142-143.

51. N. Glazer, Aflirmative Discrimination: Ethnic Inequality and Public Policy, New York, Basic Books, 1975, p. 220. 
démocraties libérales n'ont que deux choix: soit qu'elles accordent des droits nationaux à tous les groupes, soit qu'elles n'en accordent à aucun. Et comme l'octroi de droits nationaux aux groupes d'immigrants serait injuste et qu'il susciterait la division, les libéraux américains en concluent qu'ils doivent aussi refuser l'octroi de ces droits aux minorités nationales ${ }^{52}$.

\section{CONCIUSION}

Jai examiné trois facteurs ayant contribué au développement du consensus libéral d'après-guerre sur la culture: une crainte pour la paix internationale fondée sur la Realpolitik, l'adhésion au principe d'égalité raciale, et l'inquiétude au sujet des revendications croissantes des groupes d'immigrants. Chacun de ces facteurs a servi à ètouffer la question des droits des minorités nationales. Pourtant, dans chaque cas, cet effet est dû à une distortion des questions réelles. Cette confusion a engendré l'opinion voulant que les droits des minorités sont intrinsèquement injustes et qu'ils constituent une trahison de liidéal libéral d'égalité. Mais ces trois influences, lorsqu'on les examine de plus près, viennent appuyer le point de vue opposé. La première concède le caractère juste des droits des minorités, et la deuxième et la troisième plaident contre l'existence d'institutions séparées pour les groupes raciaux ou les groupes d'immigrants sur des bases qui sont compatibles avec la légitimité des droits nationaux, et qui les soutiennent même dans certains cas. Si l'on examine la pensée de théoriciens libéraux plus anciens, on trouve encore moins d'éléments venant soutenir l'orthodoxie libérale actuelle.

Je n'ai pas tenté d'identifier quelles sont les politiques relatives aux droits nationaux et à la polyethnicité qui sont compatibles avec le libéralisme let toute défense libérale des droits des minorités sera assortie de multiples contraintes, étant donné l'adhèsion libérale aux principes d'autonomie individuelle et d'égalité $)^{53}$. Il n'y a cependant pas de raison de penser que les

52. Voir par exemple les arguments pratiquement identiques de Michael Walzer dans "Pluralism in Political Perspective », dans M. Walzer, (dir.), The Politics of Elhnicity, Cambridge, Harvard University Press, 1982; et "States and Minorities", dans C. Fried, (dir.), Minorities: Community and Identity, Berlin, Springer-Verlag, 1983. Jai critiqué la conception de Walzer dans «Liberalism and the Politicization of Ethnicity », Canadian Joumal of Law and Jurisprudence, vol. 4/2,1992, pp. 253-255.

53. Il est important de distinguer deux formes de « droits des groupes ». Il y a d'une part les droits d'une culture minoritaire par rapport à une société 
revendications de droits nationaux sont intrinsèquement injus tes; je crois d'ailleurs que plusieurs de ces revendications satisferont aux critères les plus rigoureux de la justice libérale ${ }^{54}$. De toute façon, il est clair qu'une grande part de la popularité de l'orthodoxie libérale actuelle repose sur une confusion. Certains arguments liberaux pour la dépolitisation de l'ethnicité, fondés sur des présupposés s'appliquant à des cas particuliers, ont été erronément généralisés à tous les cas de pluralisme culturel. Cest là une erreur de portée considérable, car le libéralisme au Canada ne restera viable que s'il reconnaît les différentes formes de pluralisme culturel et qu'il s'y adapte.

Département de philosophie

Université d'Ottawa

plus grande, et d'autre part les droits d'une culture minoritaire par rapport à ses propres membres. Je crois que les premiers sont généralement compatibles avec le libéralisme, mais que les derniers ne le sont généralement pas. J'elabore cette distinction dans "The Rights of Minority Cultures », Political Theory, Vol. 20/t, 1992, pp. 140-146; et « Individual and Community Rights », dans Judith Baker (dir.), Group Rights, Toronto, University of Toronto Press, à paraitre.

54. Je propose un cadre pour l'évaluation des revendications des minorités, en me concentrant sur les droits des peuples autochtones du Canada, dans Liberalism, Communily, and Cullure, ch. 7 à $g$. 